\title{
Coaxial dielectric barrier discharge plasma reactor for biodiesel production from palm oil and methanol
}

\author{
Saphira Nurina Fakhri, Sari Dafinah Ramadhani, and Setijo Bismo \\ Universitas Indonesia, Faculty of Engineering, Department of Chemical Engineering, Kampus UI Depok, Depok 16424, \\ Indonesia
}

\begin{abstract}
Biodiesel is one of renewable energy alternatives, as a substitution of diesel engine fuel or diesel oil. Indonesian palm oil contains the fatty acids needed for the synthesis of FAME (fatty acid methyl ester) as the basic ingredient of biodiesel. Conventional biodiesel synthesis methods, which generally use transesterification reactions with homogeneous and heterogeneous catalysts, have significant constraints due to the formation of relatively large quantities of glycerol compounds as well as requiring complex separation processes and considerable energy. The DBD (Dielectric Barrier Dicharge) plasma reactor can be a solution to overcome the above shortcomings. The purpose of this research is to perform performance test from design result of DBD plasma reactor especially biodiesel making process. The analytical methods for FAME products use GC-FAME and FTIR (Fourier Transform Infra Red) for chemical conversion related between triglyceride reactants and biodiesel products. The best operating conditions obtained from the hydrodynamic test showed a mixed flowrate of triglyceride/alcohol of $0.1318 \mathrm{~L} / \mathrm{min}$, gas flowrate (plasma carrier) of $2.5 \mathrm{~L} / \mathrm{min}$ and a voltage of 220 Volts alternating current. Biodiesel is produced using palm oil and methanol as a liquid reactant and using argon as a plasma carrier gas in the reactor. Plasma is produced in DBD reactor using 1-phase PLN power, with a voltage of 220 VAC. The main advantage of the conversion process in this plasma reactor is the production of FAME without the formation of significant glycerin byproducts and the use of homogeneous or heterogeneous catalysts.
\end{abstract}

\section{Introduction}

These new and renewable new energy policies around the world, primarily based on environmental issues and the reduction of fossil fuel sources, have prompted the industrial world to cautiously use alternative fuels such as biodiesel. Biodiesel has been selected as an alternative fuel because of the abundance of raw materials to make biodiesel available in Indonesia.

Palm oil contains satturated fatty acid needed to make diesel fuel as the raw material. Production of biodiesel from vegetable oil with homogeneous and heterogeneous catalys have been proven in industry scale. However, conventional method with homogeneous and heteregeneous catalyst have signficant constrains such as the formation of glycerol compound in large quantities. The major problem of using homogeneous catalyst is that saponification reactions due to the reaction of $\mathrm{OH}$ groups on the catalyst with oil containing high levels of FFA (Free Fatty Acid) which can reduce the conversion of reaction and also be complicated in separation process and non-regenerating catalyst processes [1]. Besides, the acid catalyst requires a high alcohol-to-oil molar ratios and catalyst concetration to achieve satisfactory transesterification conversion [2].
Another promising method is use of plasma technology, whether plasma electrocatalyst or intergrated plasma assisted catalyst that had been applied for other synthesis. Over the past decade, non-thermal plasmas have been investigated as a way to catalyze the conversion process of various hydrocarbon fuel into syngas [3]. The non-thermal plasmas are electricallydriven ionized gases that are know to generate chemically active species such as $\mathrm{O}$ and $\mathrm{OH}$, which can act as chain-branching radicals that assist with the propagation of fuel conversion reactions and needed lower temperatue for reaction process. Dielectric barrier discharge reactor is a non thermal plasmas type that has advantages such as not requiring high pressure resistant wall, easily enlarged scale can be run continuously and the simplest construction making it easier for treatment. Vegetable oil and methanol are contacted with highenergy electrons to produce mono alkyl esters wihout any formation reaction of soap and glycerol, so it does not require separation of contaminants at the end of the process [4-6].

In this study, the conversion technology of triglyceride (from vegetable oil) into fatty acid methyl ester (FAME) or biodiesel is done in a Dielectric Barrier Discharge (DBD) type of plasma reactor or corona type.

\footnotetext{
Corresponding author: setijo.bismo@ui.ac.id
} 
The corona discharge plasma comprised of a partially ionized gas, in which the average energy of the electrons is considerably higher than the energy of the ions and the gas molecules. Plasma discharges are widely used for processing and are indispensable in many technological applications [7].

The plasma discharge is formed by applying an intense electric field, which causes the formation of an electronic self-propagating arc within the gas volume. Once the ionized gas is generated, the electrons collide with molecules, creating chemically-actives pecies known as radicals. Radicals, once produced, can replace the conventional chemical form of the catalyst during transesterification reactions, facilitating the separation of the biodiesel formed [6-8].

The corona discharge plasma reactor technology offers advantages related to the production of biodiesel compared to conventional methods due to faster reaction times and the easy separation of the final product [9-11]. In the design of reactor, information on behavior or hydrodinamic is essential. This hydrodynamic test is performed to see the flow pattern of a reactor performed by observation based on the physical form of a reactant. The prediction of the best condition operation obtained by hydrodynamic test which will be proven by doing analysis of GC-FAME \& FTIR.

\section{Methodology}

\subsection{Raw material preparation}

The raw material of triglyceride, commercial refine palm oil was purchased from local market (Tropicana), while technical methanol were used as reactant. In this study, using high purity of argon as carrier gas of plasma.

\subsection{Dielectric barrier discharge reactor}

The DBD plasma reactor was composed of a high voltage electrode, a inner electrode, and a barrier of glass material. The DBD plasma reactor used in the form of tube consists a quartz glass cylinder $(300 \times 110 \mathrm{~mm})$ surrounded by a spiral coil made of stainless steel (SS316) with length of $250 \mathrm{~mm}$, which served as an outer eletrode and the reactor length (glass) use in this study is $270 \mathrm{~mm}$. A stainless steal screw in the center of quartz tube was used to seal the exits and keep the inner electrode in the center of the tube. Selection of both electrode material because of its ability in conducting electricity to produce plasma and relatively economical. The dielectric material used in this research is quarts glass. The reasons of using this material are heat resistant, high voltage resistant and relatively econmonical. In addition, this dieletric glass will distribute the plasma so is not going to be concentrated in some points only. Inside this glass will be placed high voltage electrode so that the plasma process occurs between the outer surface with spiral electrode (Fig 1).

The used of palm oil with metahnol was introduced into reactor through an access positioned at the right side of reactor cap, throughout the process was injected 2.5
$\mathrm{L} / \mathrm{min}$ of argon into the reactor. The final product, fatty acid methyl ester (biodiesel) is pulled accros the reactor and a source of alternating current voltage of $10 \mathrm{kV}$ is used to generate the plasma.

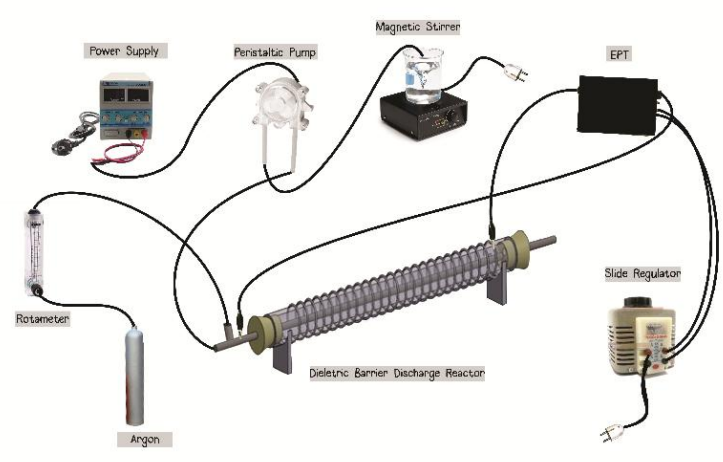

Fig. 1. A series of research equipmet. Source: Author.

\subsection{Start-up reactor test}

After arranging all equipments as a system, it is necessary to test the start-up of the tool to know the dielectric barrier discharge reactor performance. These start-up tests include leak and physical plasma test and hydrodinamic test.

\subsubsection{Leak test and physical plasma test}

After DBD plasma reactor is designed, the next steps are leak test and physical plasma test. These tests aim to look at the phenomenon emergence of plasma and determine the range of safe voltage conditions for the operation of the reactor. At first the reactor is tested for leakage by draining the aquadest and alcohol as the fluid and air from the compressor as gases. After the reactor has not leaked, the reactor is connected to a high voltage electrode from the EPT (Electronic Power Trasnfomer) and then observed.

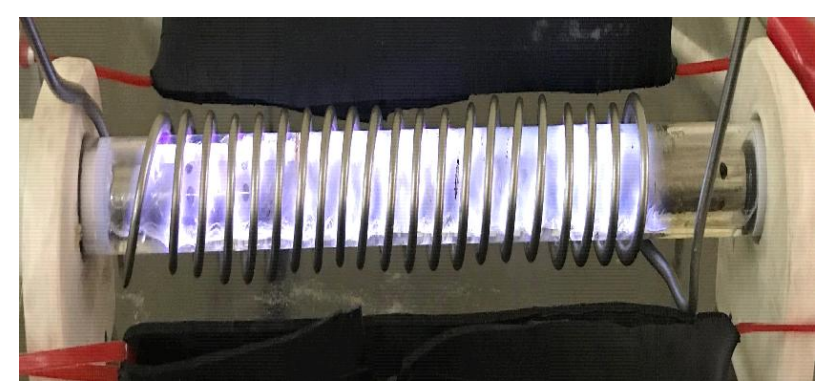

Fig. 2. Dielectric barrier discharge reactor used in the experiment.

\subsubsection{Hydrodinamic test}

In the design of reactor, information on behavior or hydrodinamic is essential. This hydrodinamic test is a preliminary study that will influence the next steps that 
occur later. Hydrodinamic reactor in dielectric barrier discharge includes gas hold up and fluid circulation rate. Usefulness of hold up gas to determine the residence time of gas in fluid. With the residence time of fluid in the gas that occurs for a long time then the contact time between the fluid reactant and plasma generated will be longer so that the reaction happens more. Therefore, it is expected to obtain a long residence time so that the reaction conversion is happening greater.

In the hydrodinamic test, palm oil and methanol are used as the reactant liquids. The gas used is the air coming from the compressor. Fluid flowrate is varied by changing the power supply at the pump with a voltgae of 5 - 7 volts or equal to $0.1136-0.15 \mathrm{~L} / \mathrm{min}$, while the gas flowrate is varied from $0.5-2.5 \mathrm{~L} / \mathrm{min}$. The aim of hydrodinamic test is to get the best operating condition. The approach adopted in the hydrodynamic test is pseudo single phase approximation, which assumes the oil and alcohol as raw materials are completely mixed well.

\subsection{Biodiesel production process}

In the production of biodiesel using plasma technology, the reaction occured inside the dielectric barrier discharge reactor after mixing raw material with short chain alcohol (in this case using technical methanol), gas argon. Molar fration of oil: methanol equal to $1: 1$. The dielectric barrier discharge reactor promoted the reaction, when the highly energetic plasma atmospher promotes the formation of methyl esters (biodiesel) in the absence of chemical catalyst, thereby replacing chemical catalyst and also reduce using of alcohol.

\section{Result and discussion}

\subsection{Start Up Reactor}

\subsubsection{Leak and Physical Plasma test}

After the absence of a leak in the next reactor is a physical test test. The purpose of this test is to obtain an appropriate voltage for generating plasma. The best condition is at 220 volt and 68 watts of power, where electric discharges with frequent intensities are formed

\subsubsection{Hydrodinamic Test}

The graph below (Fig 3.) shows relationship between gas flowrate and product flowrate with various fluid reactant flowrate. Considering the gas phase in the reactor the amount of fluid in the reactor will decrease. Then, the greater the gas flow rate will decrease the residence time of the fluid phase. The graph shows that the increase of gas flowrate will cause decrasing of product flowrate. The greater gas flowrate will result in a smaller product flowrate so that the volume of the product is also smaller, with this condition will be more ionized gas to produce plasma. In addition, with the same fluid flowrate, but the gas flowrate is enlarged then the product flowrate will be smaller so that with the increase of the gas flowrate is expected the contact time gas of fluid will be longer.

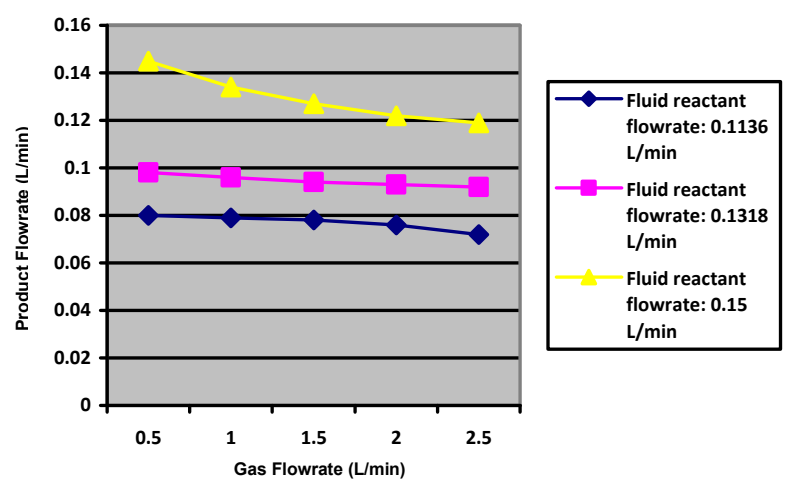

Fig. 3. Relationship between gas flowrate and product flowrate

Fig 4. shows relationship between the fluid reactant flowrate and product flowrate with variation of the gas flowrate. Fig 4. is aimed to know the optimum fluid reactant flowrate of the reactor. This graph shows the greater flowrate of the fluid reactant can increase product flowrate. At high fluid flowrate, the flow regime is in the high interaction regime so that the fluid phase pressure is strong enough to withstand the gas phase pressure so that the residence time is less affected by the gas phase. The optimum fluid reactant flowrate condition based on the hydrodinamic test is at the fluid flowrate $=0.1318$ $\mathrm{L} / \mathrm{min}$. The greater resindence time in the fluid is expected to have large conversion of product.

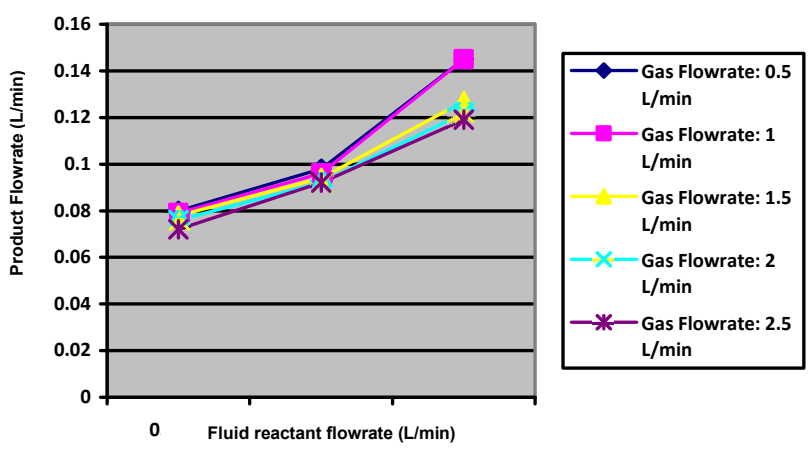

Fig. 4. Relationship between fluid reactant flowrate and product flowrate

Based on hydrodinamic test result, the proposed gas flowrate is $2.5 \mathrm{~L} / \mathrm{min}$ and fluid flowrate is $0.1318 \mathrm{~L} / \mathrm{min}$.

\subsection{Methyl ester (biodiesel) production}

The operation conditions were oil/methanol molar ratio (1:1), gas flowrate $2.5 \mathrm{~L} / \mathrm{min}$, fluid reactant flowrate $0.1318 \mathrm{~L} / \mathrm{min}$ and reaction time (1-6 hours), and in all experiments reaction were carried out in the absence of catalyst and the alcohol used was methanol as fixed variabel. The dieletric barrier discharge reactor operating in contionuous system and 220 voltage and current (AC Source) 


\subsection{Indentification of ester by FTIR and GC- FAME}

To know whether the raw materials have been converted into the desired product will be analyzed in the form of FTIR and GC-FAME. FTIR is an analysis to see the bonding structure of a compound, whereas GC-FAME to find out the \% Fatty Acid Methyl Esters formed. The first thing to do is qualitative analysis using FTIR. FTIR results seen in Fig 5.A is the raw materials, in Fig 5.B-D respectively at the $1^{\text {st }}, 2^{\text {nd }}$ and $6^{\text {th }}$ hour reaction time. Based in the FTIR test result, proven FAME formed with frequency region $\left(\mathrm{cm}^{-1}\right)$ in range $1735-1750 \mathrm{~cm}^{-1}$. The FAME compound has been formed at the start of the $1^{\text {st }}$ hour reaction time, the reaction time continues until 6 o'clock. To prove the result of FTIR test, there will be GC-FAME test to know how many \% FAME contained in a product. Based on the GC-FAME test seen in Fig 6. $\%$ Fatty Acid Methyl Ester which at the $6^{\text {th }}$ hour was $10.1 \%$. The high energetic electrons supplied from high voltage power supply are able to affect the electrons pair of covalent bondings to be excited or dissociated even
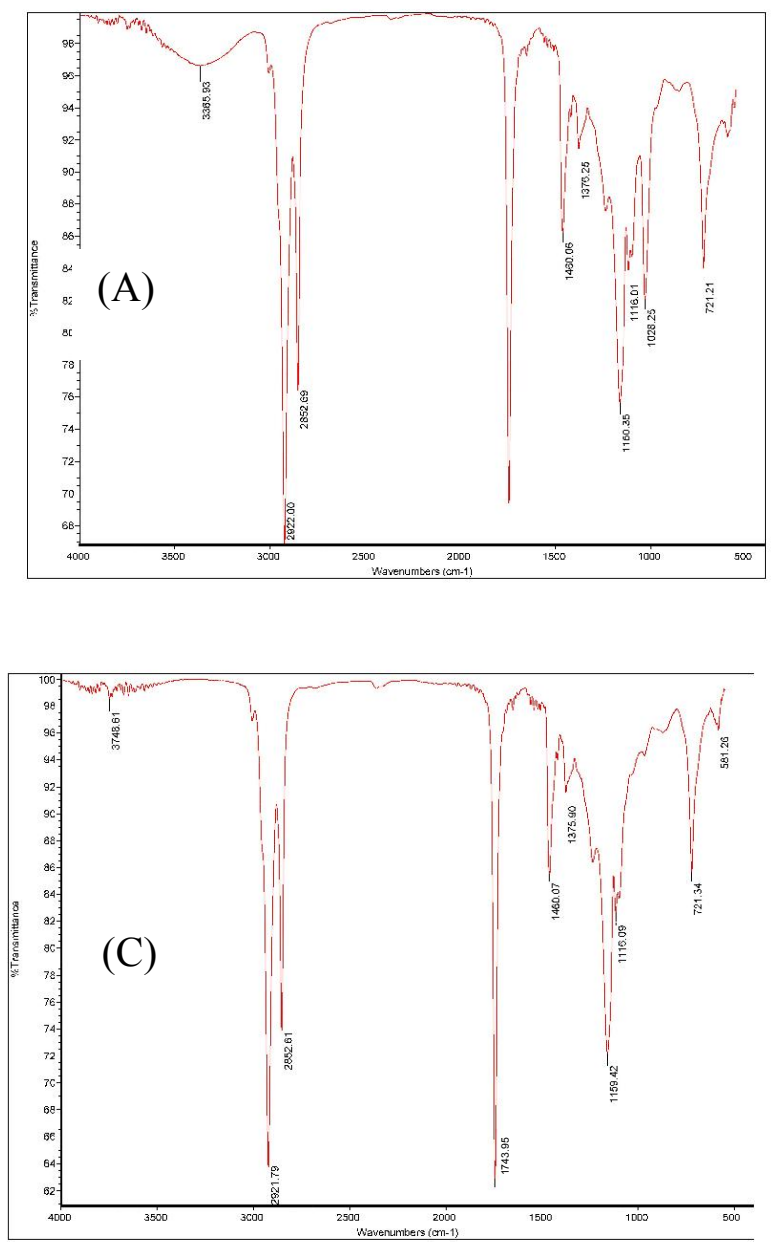

ionized depending on their energy. This means that the operating conditions obtained in accordance with the hydrodynamic test is appropriate.

\section{Conclusions}

This study showed that dielectric barrier discharge is a promising technology. Based on the results of the research, it is possible to produce biodiesel from palm oil and methanol using the design DBD plasma reactor, ie DBD plasma reactor with discharge length about 250 $\mathrm{mm}$ (above $270 \mathrm{~mm}$ ), TG/MeOH fluid flowrate of $0.1318 \mathrm{~L} / \mathrm{min}$ and a gas carrier gas flowrate of 2.5 $\mathrm{L} / \mathrm{min}$, based on the hydrodynamic test performed. The product verification result using GC-FAME also clearly indicates the formation of FAME compounds as the main product. Besides, from the results of this study, it has also been confirmed that the advantages or virtues of these design-driven DBD plasma reactors, ie, the lack of glycerin side preparation under conditions of catalyst absence.
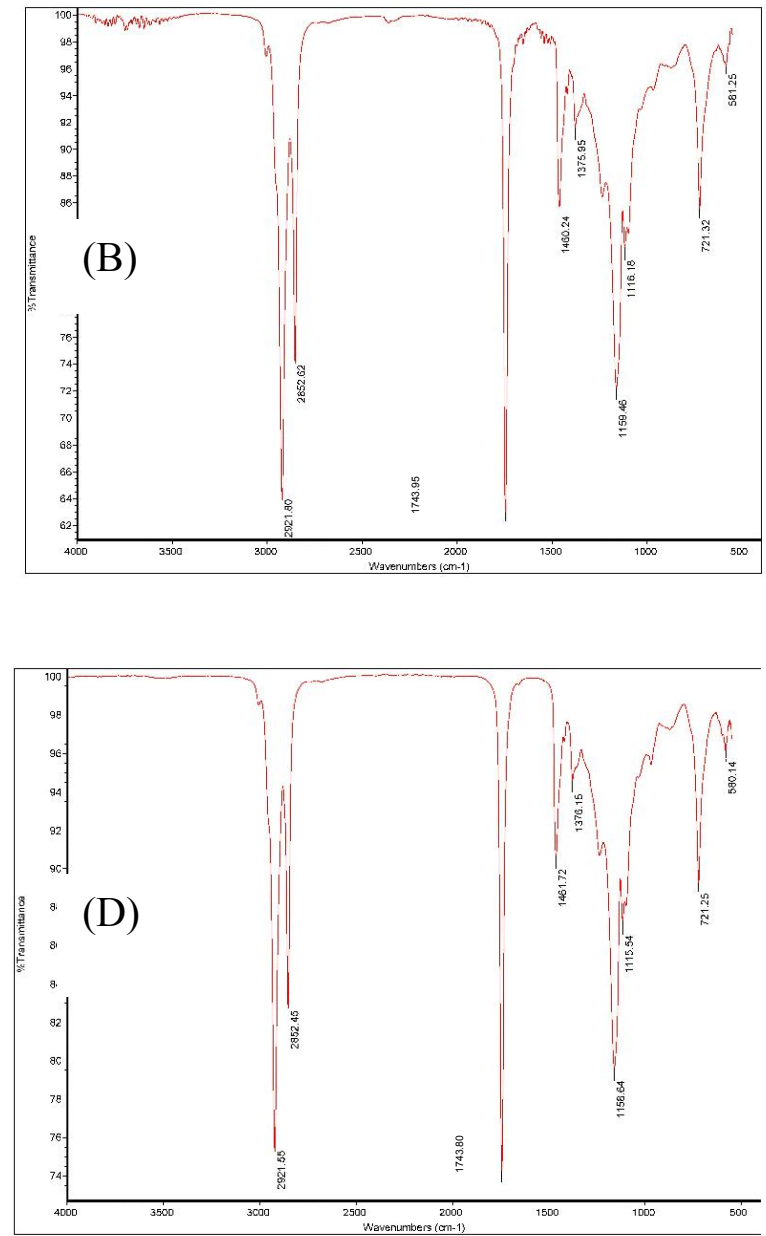

Fig. 5. FT-IR spectra of dielectric barrier discharge plasma reactor products; (A) FT-IR spectra of raw material; (B) FT-IR spectra at $1^{\text {st }}$ time reaction; (C) FT-IR spectra at $2^{\text {nd }}$ time of reaction; (D) FT-IR at $6^{\text {th }}$ time of reaction. 


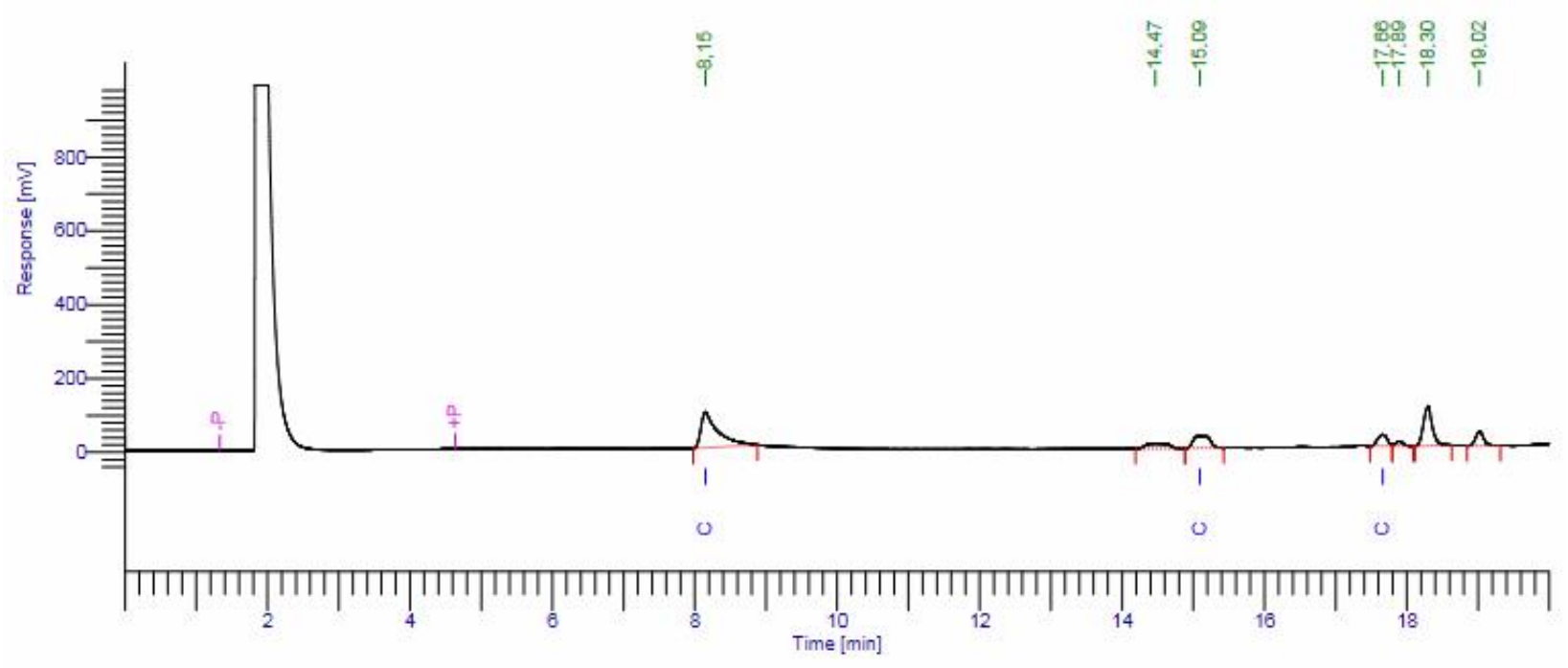

Fig. 6. GC-FAME spectra at $6^{\text {th }}$ time reaction

Have been conducted thanks to the "PITTA Grant" (Hibah Publikasi Internasional Terindeks Tugas Akhir Mahasiswa Universitas Indonesia) 2018, organized by the Directorate of Research and Community Service (DRPM) - Universitas Indonesia. The authors state that there is no competing interest or any financial conflict of interest.

\section{References}

1. Juan, J.C., Kartika, D.A., Wu, Y.T., Yun-hin, T.Y., Biodiesel production from jatropha oil by catalytic and non catalytic approches: An overview. Bioresource technology. 102. 452-460. (2011).

2. Istadi, I., Yudhistira, A. D., Anggoro, D. D. \& Buchori, L., Electro-Catalys System for Biodiesel Synthesis from Palm Oil over Dielectric - Barrier Discharge Plasma Reactor. Bulletin of Chemical Reaction Engineering and Catalysis, 2, pp. 111-120. (2014).

3. Lee, D.H., Kim, T. Plasma-catalyst hybrid methsnol-steam reforming for hydrogen production. 38(14): 6039-6043. (2013)

4. Istadi, N.A.S.A., Co-generation of synthesis gas and C2C hydrocarbons from methane and carbon dioxide in a hybrid catalytic-plasma reactor: a review. Fuel 85, 577-592. (2006).

5. Istadi, N.A.S.A., Didi, D.A., Puput, M.S., Bambang, T.N., Biodiesel production from vegetable oil over plasma reactor: optimization of biodiesel yeild using response surface mecthodology. B. Chem. React. Eng. Catal. 4 (1), 23-31. (2009).

6. Cubas, A.L.V., Machado, M.M. , Pinto, C.R.S.C., Moecke, E.H.S, Dutra, A.R.A., Biodiesel production using fatty acid from food industry waste using corona discharge plasma technology. Brazil: University of Southern Santa Catarina., 1-6. (2015).

7. Kogelschatz, U., Dielectric barrier discharge: their story, discharge physics, and industrial applications. Plasma Chem. Plasma P. 23, 1-46. (2003).
8. Cercado, A.P., Ballesteros, F.C., Capareda, S.C., Biodiesel from Three Microalgae Transesterification Processes using Different Homogenous Catalysts. IJTech. 9(4), 645-651 (2018)

9. Hidayat, A., Mukti, N.I.F., Handoko, B., Sutrisno, B., Biodiesel Production from Rice Bran Oil over Modified Natural Zeolite Catalyst. IJTech. 9(2), 400-411 (2018)

10. Ani, F.N., Said, N.H., Said, M.F.M., Optimization of Biodiesel Production using a Stirred Packed-bed Reactor. IJTech. 9(2), 219-228 (2018)

11. Milosavljevic, V., Karkari, S.K., Ellingboe, A.R., Characterization of pulse plasma source. Plasma Sourc. Sci. T. 16, 304. (2007). 